\title{
The Use of Contingency Theory in Management and Accounting Research
}

\author{
Kamisah Ismail ${ }^{1}$, Suria Zainuddin and Noor Sharoja Sapiei
}

\begin{abstract}
Contingency theory has been widely accepted and used in management and accounting literature. It works based on the principle that the appropriateness of managerial techniques or systems is contingent upon the setting of that organisation. Contextual factors may explain the reasons for different systems that suit different organisations differently. This paper discusses the effect of the contextual factors (external environment, technology, structure, culture, size, and strategies) that may affect the organisation's structure, and, consequently, affect the design of the accounting information system.
\end{abstract}

Keywords: Contingency theory, accounting

\section{Introduction}

According to Otley (1980), the concept of contingency was first developed in the organisation theory literature in the early to mid-1960s, however, its application in accounting research was insignificant before the mid-1970s. Contingency theory states that efficient organisation structures vary with organisational contextual factors, such as technology and the environment. It further implies that the effectiveness of certain managerial techniques is contingent on the organisation's context and structure (Lawrence and Lorsch, 1967; Waterhouse and Tiessen, 1978; 1983). In the context of management accounting, contingency theory is based on the premise that there is no universally appropriate accounting system that applies equally to all organisations in all circumstances (Otley, 1980). Factors, such as technology and the environment, are among the contextual factors that could explain why accounting systems have been found to differ from one organisation to another. These contextual factors will affect the organisation's structure, which will then influence the design of the accounting information system.

Haldma and Laats (2002) reclassified these contextual factors into external and internal factors. They argued that the effectiveness of the design of an

Corresponding author: Dr Kamisah Ismail is a Lecturer at the Faculty of Business and Accountancy, University of Malaya, email: kamisah.ismail@um.edu.my. Dr. Suria Zainuddin is a Lecturer at the Faculty of Business and Accountancy, University of Malaya and Dr Noor Sharoja Sapiei is a Senior Lecturer at the Faculty of Business and Accountancy, University of Malaya. 
accounting system depends on its ability to adapt to changes in external and internal circumstances. In management research, the main external factors that have been investigated are external environment (Khandwalla, 1972; Hambrick, 1981; Gordon and Narayanan, 1984; Swamidass and Newell, 1987; Anderson and Lanen, 1999; Saudagaran and Diga, 1999; Mia and Clarke, 1999; Chong and Rundus, 2004; Agbejule and Burrowes, 2007; Patiar and Mia, 2008; Ax et al., 2008), and national culture (Hofstede, 1984; O’Connor, 1995; Tsui, 2001; Henri, 2006). The internal contextual factors that have been investigated are technology (Chenhall and Morris, 1986; Mia and Chenhall, 1994; Kalagnanam and Lindsay, 1999), structure (Burns and Stalker, 1961; Lawrence and Lorsch, 1967; Brownell, 1985; Lee and Yang, 2010), organisational size (Hendricks and Singhal, 2001; Martinez-Lorente et al., 2004), and company strategies (Miles and Snow, 1978; Porter, 1980; Miller and Friesen, 1982; Gupta and Govindarajan, 1984; Simons, 1987; Frey and Gordon, 1999; Jermias and Gani, 2004; Boulianne, 2007; Cadez and Guilding, 2008).

A review of the literature on contingency theory shows that this theory originated from theorists, such as Burns and Stalker (1961), Thompson (1967), Lawrence and Lorsch (1967), Perrow (1970), and Galbraith (1973). The early works on this theory examined the impact of the environment and technology on organisational structure. Since then, contingency theory has been applied and widely used in management and accounting research. More recently, the impact of new contextual factors, such as contemporary technology and strategy are examined. Chenhall $(2003 ; 2007)$ provided a comprehensive review of the application of contingency theory in management control research. To further understand this theory, the effects of each contextual factor - external environment, technology, structure, culture, size, and strategies - are discussed.

\section{Contextual Factors}

\subsection{The External Environment}

The earliest contextual factor that has been examined in the contingency-based research is the impact of the external environment (Burns and Stalker, 1961; Galbraith, 1973; Lawrence and Lorsch, 1967; and Perrow, 1970). The external environment is also considered as a powerful contextual factor and forms a base in contingency studies (Chenhall, 2003; 2007). The two most commonly researched factors of the external environment are market competition and perceived environmental uncertainty (PEU). The work of Khandwalla (1972) is among the earliest empirical studies examining the impact of the external environment. Specifically, he examined the effects of different types of competition (price, product, and distribution) on the use of controls by manufacturing firms.

Hambrick (1981) examined the relationship of the environment and strategy on the power of top management teams. The findings from three distinct industries (private general hospitals, life insurance firms, and private colleges) suggest that 
different industry environments affect the relationship between functional areas and the power of top management teams. For example, insurance firms that faced an environmental requirement for product/market innovation, involvement in the marketing and product development functions had a positive relationship with power. In contrast, hospitals that faced an external requirement for efficiency and cost control, the accounting/finance, process improvement and operations functions were positively related to power. Colleges did not face any dominant environmental requirement, thus, the relationship between the functional areas and the power of top management teams was muted and mixed.

Gordon and Narayanan (1984) investigated the impact of contextual variables on the design and perceived usefulness of management accounting systems (MAS) in organisations. Contextual variables used in this study are PEU and organisation structure. Using a cross-sectional study from 34 profitoriented, medium-size, Midwestern domiciled firms in the major cities of the states of Kansas and Missouri, they examined the relationships between an organisation's PEU, its structure and its information system. They found that a higher PEU is associated with organic types of organisational structure, and with higher perceived importance attached to information characterised as being external, non-financial and ex-ante. In contrast, a lower PEU is associated with mechanistic types of organisational structure, with lower perceived importance attached to external, non-financial and ex-ante information. In other words, when greater environmental uncertainty is perceived, decision makers tend to seek external, non-financial and ex-ante information in addition to other types of information and increasingly move towards an organic form of organisation. The results of the study indicate that the environment is an important factor in designing accounting systems. Characteristics of information that are useful will depend on the type of environment. Managers facing high environmental uncertainty use more information for decision making.

Similarly, using interview data from 68 manufacturing companies in Sydney, Chenhall and Morris (1986) also found that PEU was associated with broad scope and timeliness. Managers who perceive the environment as uncertain for planning and control may rely on broad scope information provided by MAS. A broad scope MAS will provide information relating to the external environment, which may be economic, such as market share, or non-economic, such as demographic factors, as well as predicting the occurrence of possible future events. Managers in uncertain environments also need to respond quickly to unpredictable situations. As such, timely information is very useful.

Based on the data from 35 manufacturing firms in Seattle, Swamidass and Newell (1987) found that PEU influences manufacturing strategy, which, in turn, influences business performance. This study measured manufacturing strategy in terms of flexibility and the role of manufacturing managers in strategic decision making. More recently, Agbejule and Burrowes (2007) studied the relationship between PEU, supplier development, and the use of MAS information in 
manufacturing firms in Finland. The responses from 78 managers confirmed that PEU is a determinant of supplier development, which, in turn, influences the use of broad scope MAS. Their finding is consistent with the studies of Gordon and Narayanan (1984), and Chenhall and Morris (1986).

Anderson and Lanen (1999) explored the evolution of management accounting practices in 14 Indian firms in 1996. They studied the contingent relationship between external competition and management accounting practices and explored the potentially mediating effects of firms' competitive strategies. They found that changes in the external environment prompt changes in organisational strategy and structure, which support the contingency theory. The changes in management accounting practices (planning and control, performance measurement, and cost management) also depend on whether firms adopted 'defender' or 'prospector' strategies and whether they were domestic or international.

In financial accounting, Saudagaran and Diga (1999) used the contingency approach in comparative international accounting. They postulated that financial accounting systems are related, on a contingent basis, to particular environmental variables; namely, political, economic and socio-cultural. Recently, Abdel-Kader and Luther (2008) empirically examined ten contingency factors that influence management accounting sophistication of the UK's food and drink industry. Consistent with previous studies (e.g. Gordon \& Narayanan, 1984 and Chenhall \& Morris, 1986), the survey results suggest that PEU significantly explains the differences in management accounting sophistication. Firms that perceive a higher degree of environmental uncertainty adopt more sophisticated management accounting practices than firms that perceive lower environmental uncertainty.

Advancement in technology, availability of a variety of new products, more competitive prices and efficient marketing channels by competitors have transformed the business environment into a rapidly changing and dynamic business environment. These factors have contributed significantly to the competitive environment faced by organisations all over the world. The market competition faced by organisations has a major impact on the operation and survival of businesses. Therefore, managers should be aware of the degree of competition faced by the firms before planning the control systems in their organisations. Khandwalla (1973) revealed that, in general, competition is positively related with all four types of top management authority and controls, namely, decentralisation of decision making authority, use of sophisticated management controls, selectivity in the delegation of authority and use of controls. Mia and Clarke (1999) and Hoque (2011) found that the intensity of market competition influences firms to use MAS information. Patiar and Mia (2008) showed that market competition has a negative impact on firms' financial performance.

The increasing competition faced by organisations also influences them to adopt certain practices. For example, Das et al. (2000) showed that international 
competition influenced the US manufacturing firms to improve their supply chain management, quality training, quality resources and evaluation, and customer commitment. The findings of Chong and Rundus (2004) and Ax et al. (2008) also suggest that organisations should adopt TQM and target costing when they face increasing levels of competition.

\subsection{Technology}

Several definitions of technology exist in prior literature. As noted by Waterhouse and Tiessen (1978), Woodward (1965) defined technology in terms of the physical flow of production. However, Waterhouse and Tiessen (1978) defined technology as the routineness or non-routineness of the conversion process of raw materials. Chenhall $(2003 ; 2007)$ defined technology as including the hardware, software, materials, people, and knowledge that are involved in the organisation's work processes. He further categorises technology into two types: generic and contemporary. Generic technology includes complexity, interdependence and task uncertainty, while contemporary technology refers to advanced technology.

Complexity refers to standardisation of work. Highly specialised, nonstandard, and differentiated products represent increasing levels of complexity, which require complex unit and batch technologies. In contrast, standard and undifferentiated products that require mass production and process technologies represent decreasing levels of complexity.

Interdependence means the extent to which it has to depend on others in completing a task or process. There are three types of interdependence: pooled, sequential, and reciprocal. Being the lowest form, pooled interdependence depends less on others, while sequential interdependence is dependent upon the workflow of others. If the first unit does not complete the task, then the second unit cannot proceed with its work. Reciprocal interdependence is the highest form of interdependence, where the work flows back and forth between units. Chenhall and Morris (1986) found that organisational interdependence is associated with broad scope, aggregated and integrated information. Thus, managers must consider the level of interdependence before designing MAS.

Task uncertainty refers to the variability in the tasks and the analysability of methods in performing the tasks. Mia and Chenhall (1994) demonstrated that different departments face different levels of task uncertainty. They found that marketing departments, which face more uncertainty, tend to use broad scope MAS more than production departments, which involves more certain tasks.

In today's competitive environment, the manufacturing processes have become more complex, which requires more sophisticated and advanced technologies. Contemporary technologies, such as Just In Time (JIT), Total Quality Management (TQM) and Flexible Manufacturing (FM), have become the new contextual factors of technology (Chenhall, 2003; 2007). Kalagnanam and Lindsay (1999) utilised both case study and survey methods to study the use 
of organic models of control in JIT manufacturing firms in Canada. The results from the three case studies and 155 survey responses indicate that JIT firms move towards an organic rather than a mechanistic form of management control system. The firms used more informal and cross-functional communications, decentralised decision making, participation and teamwork integration. The authors provided three reasons for the adoption of organic control by JIT firms. First, the increase in the degree of coupling among processes due to the decreased time in task variability, and second, the nature of JIT system, which is more flexible in terms of production mix. In order to fulfil customer demand, minimise costs, ensure higher quality products and on time delivery, production flexibility requires integration and coordination among various parties. Lastly, JIT philosophy, which focuses on continuous improvement through the elimination of waste, needs cooperation from all workers.

Using JIT, TQM and Advanced Manufacturing Technology (AMT) as contextual variables, Abdel-Kader and Luther (2008) showed that these firms adopt more sophisticated management accounting practices. Thus, in line with the advancement in technology, and as suggested by Chenhall (2003; 2007), JIT, TQM and AMT are regarded as new contextual factors that could explain organisational behaviour.

\subsection{Structure}

Similar to technology, various definitions exist for organisational structure. Burns and Stalker (1961) defined structure in terms of mechanistic and organic types. Mechanistic types of organisational structure involve reliance on formal rules, procedures and routines, whereas organic types, involve fewer rules and procedures, and tend to be more flexible. As discussed in the previous section, Gordon and Narayanan (1984) found that lower (higher) PEU is associated with mechanistic (organic) types of organisational structure. Kalagnanam and Lindsay (1999) discovered that JIT firms tend to use an organic form of control rather than mechanistic due to their nature of system. These two studies show that the discussion of organisational structure in contingency-based research is normally related to other contextual factors, such as the environment or technology.

In addition, a recent study by Lee and Yang (2010), which investigated the effect of organisation structure and competition on the design of performance measurement systems of Taiwanese firms, demonstrated that organisational structure is significant and positively related to the design of performance measurement systems. The survey data from 168 firms listed on the Taiwan Stock Exchange showed that organic organisations rely more on integrated performance measures and higher developmental stages of performance measurement systems compared to mechanistic organisations. However, no such support was found for the effect of competition on the design of performance measurement systems. They also found that the positive effect of the use of integrated measures on 
organisational performance is stronger in mechanistic organisations than in organic organisations due to the characteristics of the mechanistic structure, which involves highly specified or formalised procedures and the centralisation of decision making.

Organisational structure is also defined as the way in which organisations are differentiated (Lawrence and Lorsch, 1967). Decentralisation is a mechanism of differentiation. Chenhall and Morris (1986) revealed that decentralisation is associated with aggregated and integrated MAS information. Mia and Chenhall (1994) concluded that functional differentiation also has an impact on the use of broad scope information in improving the performance of managers. The greater task uncertainties faced by marketing departments influence the use of more MAS information compared to production departments to enhance managers' performance. In budgeting, Brownell (1985) investigated functional differentiation between research and development (R\&D) and marketing departments on budget participation. Based on the data from questionnaires and unstructured interviews, he concluded that budget participation is more effective in $R \& D$ than in marketing departments. Budget participation in R\&D departments was found to have a greater positive relationship with managerial performance than its counterparts.

Abdel-Kader and Luther (2008) also classified decentralisation as a type of firm structure. This organisational characteristic was found to affect the level of adoption of certain management accounting practices. Decentralised firms adopt more sophisticated management accounting practices than centralised firms. This result suggests that decentralised firms require more sophisticated management accounting practices to assist them in planning, controlling and decision making.

\subsection{Size}

Size refers to how big an organisation or a plant is. Size is usually measured by the number of employees (Mia and Chenhall, 1994; Martinez-Lorente et al., 2004; Isa, 2005; Boulianne, 2007; Mia and Winata, 2008, Dal Pont et al., 2008), sales turnover or revenue (Martinez-Lorente et al., 2004; Boulianne, 2007) and total assets (Abdel-Kader and Luther, 2008). Similar to structure, size has been studied together with other dimensions of context, such as technology and structure. In operations management contingency research, the effect of size has been investigated in order to examine the applicability of certain practices in smaller firms. For example, Martinez-Lorente et al. (2004) also showed that the implementation of TQM and Information Technology (IT) are affected by company size. Larger firms are found to have a higher implementation level on both TQM and IT than smaller firms. Hendricks and Singhal (2001) asserted that firm size moderates the benefit of TQM implementation. However, they showed that smaller firms benefit more from TQM as compared to larger firms, even though both types of firm showed a positive relationship with profitability. 
In management accounting and control research, Mia and Chenhall (1994) used large manufacturing firms as an indicator for formal financial control systems. They believed that large firms tend to adopt more formal control systems due to their size. Agbejule and Burrowes (2007) also chose medium to large sized firms due to the higher likelihood of adopting MAS and manufacturing strategies. Similarly, Abdel-Kader and Luther (2008) found that large firms adopt more sophisticated management accounting practices compared to small firms. The possible explanation could be because larger firms have financial capabilities and resources to adopt more advanced techniques and practices.

\subsection{Strategy}

Even though strategy is not a part of contextual factors, as contended by Chenhall (2003; 2007), numerous studies have considered strategy as an important element of organisational effectiveness. This could be due to the importance of strategy to achieve competitive advantage, and, subsequently, enhance organisational performance. Each organisation is unique, and, therefore, different organisations may adopt different strategies that are best suited to their own objectives, environment, structure, and culture.

There are different taxonomies that explain different types of business strategies. Miles and Snow (1978), for example, differentiate strategy into prospectors, analysers, defenders and reactors; Porter (1980) classifies business strategy into product differentiation, cost leadership and focus group; Miller and Friesen (1982) categorised business strategy into entrepreneurial and conservative; and Gupta and Govindarajan (1984) grouped the strategies into build, hold, harvest and divest. Among these taxonomies of strategies, the two most frequently used taxonomies in business and management research are Miles and Snow's (1978), and Porter's (1980) typology of strategies. However, as asserted by Abdel-Kader and Luther (2008, p. 8), "these taxonomies are not significantly different and can be reconciled with prospectors/builders/product differentiators at one end of a continuum and defenders/harvesters/cost-leaders at the other end".

Hambrick (1981) considered strategy as a critical contingency for organisations. He examined the contingent effect of strategy on the relationship between functional areas and top management power in three distinct industries. His findings indicate that in defender colleges, involvement in the marketing and product/service development was negatively related to the power of top management teams, while in prospector colleges, it was not related to power. A similar result was also found in hospitals and no support for the relationship between marketing and product/service development and top management power was found in insurance firms. The findings imply that top management power is affected by strategies adopted by organisations. The same functional area also affected top management power differently, depending on the strategy and industry to which it belongs. Therefore, the effectiveness of organisational 
strategy, in particular, functional areas, depends on the type of industry in which it operates.

Simons (1987) investigated the relationship between business strategy and accounting control systems in 108 Canadian manufacturing firms from 28 industries. The findings suggest that firms following different strategies employ different accounting control systems. Consistent with the theory, prospector firms place less emphasis on cost control and high performing prospector firms place greater emphasis on forecast data in control systems, setting tight budget goals, and monitoring outputs. Large prospector firms also focus on frequent reporting and the use of uniform control systems while large defender firms seem to use their control systems less intensively. Negative relationships were also observed between performance and control attributes, such as tight budget goals and output monitoring for defender firms. These findings support contingency theory that accounting control systems should be designed specifically to suit the business strategy of the firm.

Frey and Gordon (1999) employed Porter's (1980) classification of strategy to examine whether the performance of Activity Based Costing (ABC) practices are contingent upon the competitive strategy employed by a business unit. The responses from 123 senior financial officers indicate that $\mathrm{ABC}$ is associated with higher returns on investment (ROI) in business units following a differentiation strategy but not in those following a cost leadership strategy. As such, the benefits derived from $\mathrm{ABC}$ implementation are contingent on the competitive strategies employed by a business unit.

Using the fitness landscape approach, Jermias and Gani (2004) developed and measured the contingent fit between strategic priorities and its contextual variables and investigated the association between the level of contingent fit and effectiveness at business unit levels. Based on personal interviews and a mail survey of 106 general managers, controllers and management accountants of companies listed on the Jakarta Stock Exchange under the consumer goods industry, they found that product differentiation companies put more emphasis on behavioural, and use more management accounting systems that enhance the ability of companies to differentiate their products and to satisfy their customers (MAS type I). However, low cost strategies emphasise output more, and use more management accounting systems that enhance companies' ability to control costs (MAS type II). They also found support for a contingent fit between strategy and contextual variables, which, in turn, positively affect business unit effectiveness. Boulianne (2007) also found that the fit between strategic choice and the use of AIS could improve business unit performance. The study showed that the use of broad scope AIS by prospector and defender firms led to enhanced performance.

Cadez and Guilding (2008) used an integrated contingency model to examine the effect of four contingency factors (business strategy, deliberate strategy formulation, market orientation, and company size) on strategic management accounting (SMA) of 193 large Slovenian companies. The study 
found that SMA usage is positively associated with three of the four contingency factors (adoption of a prospector strategy, deliberate strategy formulation, and company size), and accountants' strategic decision making participation, which, in turn, positively affects performance. The results support the contingency theory's premise that organisational performance depends on the fit between the organisational context and structure and that there is no universally appropriate SMA system. Factors, such as strategy and company size, have a significant impact on the successful application of SMA.

\subsection{Culture}

Different countries and different organisations have different cultural characteristics. Thus, culture can be grouped either as national or organisational culture. As contingency theory postulates that there is no universally appropriate accounting system that applies equally to all organisations in all circumstances, different cultural values may influence the choice of accounting system in organisations. In the operations management field, the influence of culture is usually examined because most of its best practices, such as JIT and TQM, originated from one country, Japan. Therefore, there is a need to examine the effectiveness of these practices in different countries and cultures (Sousa and Voss, 2008).

Hofstede (1984, p. 389) defined culture as "the collective programming of the mind which distinguishes the members of one category of people from those of another". He further characterised culture into four categories: power distance, individualism, masculinity, and uncertainty avoidance.

Although inequality is common in every society, the acceptance varies between societies. Power distance considers a situation in which the less powerful person in a society accepts inequality in power as a norm. Individualism protects their own interests and that of their immediate family more than others. Conversely, collectivism considers that every member of a society belongs to one or more groups that cannot be detached. Each group will protect its members' interests and is tightly integrated.

Masculinity differentiates social roles for men and women. Men are expected to be assertive, ambitious, and competitive, to strive for material success, and to be respected. Whereas women are expected to serve and care for the nonmaterial quality of life, for children, and for the weak. In contrast, femininity does not differentiate social roles between sexes. Both men and women may choose a different quality of life than material success, interpersonal relationships and concern for the weak.

Uncertainty avoidance prefers to avoid uncertainty (unstructured, unclear, or unpredictable situation), and, thus, relies on rules and structures. Strong uncertainty avoidance cultures are active, aggressive, emotional, security seeking, and intolerant. Cultures with weak uncertainty avoidance are contemplative, less aggressive, unemotional, accepting of personal risk, and relatively tolerant. 
Contingency-based research often used these cultural characteristics. For instance, O'Connor (1995) examined whether the differences in organisational culture between Singapore and foreign manufacturing firms affect the usefulness of budgetary participation in a high power distance nation, such as Singapore. The findings from the interviews and survey of 125 responses from 44 manufacturing firms reveal that power distance moderates the usefulness of participation in budget setting and performance evaluation at the organisational culture level in decreasing role ambiguity and improving superior/subordinate relationship. The relationships between role ambiguity and superior/subordinate relationships as well as budget participation and performance evaluation were found to be stronger in foreign firms than local Singapore entities.

Tsui (2001) postulated that the relationship between MAS and budgetary participation on managerial performance is different depending on the cultural background of the managers. For Chinese managers, with a large-power distance, high-collectivist, and long-term orientation society, the positive relationship between MAS and managerial performance decreases as budgetary participation increases. For Western managers, low levels of budgetary participation are associated with a negative relationship between managerial performance and MAS, however, this relationship becomes positive at high levels of budgetary participation. These results were based on the questionnaire survey of 51 Chinese subunit managers in Chinese manufacturing firms in Xian, China, and 38 Caucasian expatriate subunit managers in manufacturing firms in Hong Kong.

Henri (2006) defined organisational culture in terms of two attributes: control and flexibility. He examined the relationship between organisational culture and performance measurement systems. The survey data from 383 Canadian manufacturing firms suggests that top managers of flexibility value firms tend to use performance measurement systems to focus organisational attention, support strategic decision making and legitimise actions to a greater extent than top managers of control value firms. Flexibility value firms also used more performance measures in terms of a broad set of financial and nonfinancial measures than control value firms. Thus, organisational culture does have an impact on management control systems of an organisation as measured by performance measurement systems.

\section{Arguments against Contingency Theory}

Contingency theory has been widely used as a basis for examining the characteristics of the management accounting system that works best in one organisation. Nevertheless, the application of contingency theory is not without its opponents. Contingency theory emphasises that the design and functioning of control systems in organisations are contingent upon the contextual factors, such as the technology and environment in that organisation in which these controls operate and function. However contingent factors that affect the efficiency and 
effectiveness of the system may well be accepted at the adoption stage but not at the implementation stage (Chenhall, 2003). Thus applying only contingency theory may not be adequate. This is because the implementation stage is more affected by organisational factors rather than contextual factors. Thus, the application of other theories, such as organisational theory, may be more suitable.

Moreover, in the current competitive environment, the relationships among technology, structure, and organisational effectiveness are more complicated than assumed by contingency theory. Chenhall (2003) asserted that there is no such "contingency theory", but "rather a variety of theories that may be used to explain and predict the conditions' (p. 157) in which a particular system or technique may increase the performance of the organisation. Thus, there is a need for the application of other theories, other than or complementary to contingency theory.

Further, Schoonhoven (1981) also claimed that contingency theory is not a theory, but 'it is more on orienting strategy or metatheory' (p. 350), which suggests ways of conceptualising or explaining a phenomena that rely on a few assumptions. Contingency theory also requires all the factors of an organisation to fit well with each other in order to maximise management effectiveness. However, Schoonhoven (1981) argued the usefulness of contingency theory in explaining differences in the structure and effectiveness of organisations. Quoted based on the study of Mohr (1971) and Pennings (1975), they are unable to find support that organisational effectiveness is a function of the goodness of fit between environmental and structural variables. Moreover, obsolete information and irrelevant control information may deter the ideal fit which would cause a lack of coordination, miscommunication, misunderstanding, which lead to poor organisational performance (Selto et al., 1995).

Previous tests of contingency theory have found mixed results ranging from significant to non-significant correlations between measures of fit and performance. These mixed results may be related to the ambiguity in the operationalisation of the concept of fit in contingency theory. Thus, the standard operationalisation of the concept of fit must be constructed to enable the valid interpretation of contingency theory.

\section{Conclusion}

The objective of this paper is to discuss the use of contingency theory in management and accounting research. Different systems or techniques may work well in one organisation but not in others since they depend on the setting of the organisation. It also means that no one appropriate accounting system can be applied to all organisations because there are contextual factors that could explain the reasons for accounting systems to differ from one organisation to another. This paper has discussed the effect of external environment, technology, structure, culture, size, and strategies as contextual factors that may affect 
the organisation's structure, which, consequently, influence the design of an accounting information system.

The use of contingency theory is not without criticism, nevertheless the advantages arising from using contingency theory may compensate its limitations. Contingency theory has become the dominant theory that has been widely accepted and used in management and accounting research.

\section{References}

Abdel-Kader, M. and Luther, R. (2008). The impact of firm characteristics on management accounting practices: A UK-based empirical analysis. The British Accounting Review, Vol. 40, pp. 2-27.

Anderson, S. and Lanen, W. (1999). Economic transition, strategy and the evolution of management accounting practices: the case of India. Accounting, Organizations and Society, Vol. 24, pp. 379-412.

Agbejule, A. and Burrowes, A. (2007). Perceived environmental uncertainty, supply chain purchasing strategy, and use of MAS information: An empirical study of Finnish firms. Managerial Auditing Journal, Vol. 22, No. 9, pp. 913-927.

Ax, C., Greve, J. and Nilson, U. (2008). The impact of competition and uncertainty on the adoption of target costing. International Journal of Production Economics, Vol. 115, pp. 92-103.

Boulianne, E. (2007). Revisiting fit between AIS design and performance with the analyzer strategic type. International Journal of Accounting Information Systems, Vol. 8, pp. 1-16.

Brownell, P. (1985). Budgetary systems and the control of functionally differentiated organizational activities. Journal of Accounting Research, Vol. 23, No. 2, pp. 502-512.

Burns, T. and Stalker, G. (1961). The management of innovation. London: Tavistock.

Cadez, S. and Guilding, C. (2008). An exploratory investigation of an integrated contingency model of strategic management accounting. Accounting, Organizations and Society, Vol. 33, pp. 836-863.

Chenhall, R. H. (2003). Management control systems design within its organizational context: findings from contingency-based research and directions for the future. Accounting Organizations and Society, Vol. 28, pp. 127-168.

Chenhall, R. H. (2007). Theorizing contingencies in management control systems research. In Chapman, C., Hopwood, A. and Shields, M. (eds) Handbook of Management Accounting Research (Vol. 2). Elsevier.

Chenhall, R. H. and Morris, D. (1986). The impact of structure, environment, and interdependence on the perceived usefulness of management accounting systems. The Accounting Review, Vol. LX1, No. 1, pp 16-35. 
Chong, V. K. and Rundus, M. J. (2004). Total quality management, market competition and organizational performance. The British Accounting Review, Vol. 36, pp. 155-172.

Dal Pont, G., Furlan, A. and Vinelli, A. (2008). Interrelationships among lean bundles and their effects on operational performance. Operations Management Research, Vol.1, pp. 150-158.

Das, A., Handfield, R. B., Calantone, R. J. and Ghosh, S. (2000). A contingent view of quality management - the impact of international competition on quality. Decision Sciences, Vol. 31, No. 3, pp. 649 - 690.

Frey, K. and Gordon, L. A. (1999). ABC, strategy and business unit performance. International journal of Applied Quality Management, Vol. 2, No. 1, pp. $1-23$.

Galbraith, J. (1973). Designing complex organizations. USA: Addison Wesley Publishing Company.

Gordon, L. A. and Narayanan, V. K. (1984). Management accounting systems, perceived environment uncertainty and organization structure: an empirical investigation. Accounting Organizations and Society, Vol. 9, No. 1, pp. $33-47$.

Gupta, A. K. and Govindarajan, V. (1984). Business unit strategy, managerial characteristics, and business unit effectiveness at strategy implementation. Academy of Management Journal, Vol. 27, No. 1, pp. 25-41.

Haldma, T. and Laats, K. (2002). Contingencies influencing the management accounting practices of Estonian manufacturing companies. Management Accounting Research, Vol. 13, pp. 379-400.

Hambrick, D. C. (1981). Environment, strategy, and power within top management teams. Administrative Science Quarterly, Vol. 6. No. 2, pp. 253-275.

Henri, J. F. (2006). Organizational culture and performance measurement systems. Accounting, Organizations and Society, Vol. 31, pp. 77-103.

Hendricks, K. B. and Singhal. V. R. (2001). Firm characteristics, total quality management, and firm performance. Journal of Operations Management, Vol. 19, pp. 269-285.

Hofstede, G. H. (1984). The cultural relativity of the quality of life concept. Academy of Management Review, Vol. 9, pp. 389-398.

Hoque, Z. (2011). The relations among competition, delegation, management accounting systems change and performance: A path model. Advances in Accounting, incorporating Advances in International Accounting, doi:10.1016/j.adiac.2011.05.006

Isa, C. R. (2005). The effects of competition advanced manufacturing technology and management accounting change on performance. Unpublished $\mathrm{PhD}$ thesis, Universiti Putra Malaysia.

Jermias, J. and Gani, L. (2004). Integrating business strategy, organizational configurations and management accounting systems with business unit 
effectiveness: a fitness landscape approach. Management Accounting Research, Vol. 15, pp. 179-200.

Kalagnanam, S. S. and Lindsay, R. M. (1999). The use of organic models of control in JIT firms: generalizing Woodward's findings to modern manufacturing practices. Accounting, Organizations and Society, Vol. 24, pp. 1-30.

Khandwalla, P. N. (1972). The Effect of Different Types of Competition on the Use of Management Controls. Journal of Accounting Research, Vol. 10, No. 2, pp. 275-285.

Khandwalla, P. (1973). Effect of competition on the structure of top management control, Academy of Management Review, Vol. 16, No. 2, pp. 285-295.

Lawrence, P. and Lorsch, J. (1967). Organization and environment. Homewood, Ill: Irwin.

Lee, C.-L., Yang, H.-J. (2010). Organization structure, competition and performance measurement systems and their joint effects on performance. Management Accounting Research, doi:10.1016/j.mar.2010.10.0.

Martinez-Lorente, A. R., Sanchez-Rodriguez, C. and Dewhurst, F. W. (2004), The effect of information technologies on TQM: An initial analysis. International Journal of Production Economics, Vol. 89, No. 1, pp. 77-93.

Mia, L. and Chenhall, R. H. (1994). The usefulness of management accounting systems, functional differentiation and managerial effectiveness. Accounting, Organizations and Society, Vol. 19, No. 1, pp. 1-13.

Mia, L. and Clarke, B. (1999). Market competition, management accounting systems and business unit performance. Management Accounting Research, Vol. 10, pp. 137-158.

Mia, L. and Winata, L. (2008). Manufacturing strategy, broad scope MAS information and information and communication technology. The British Accounting Review, Vol. 40, pp. 182-192.

Miles, R. W. and Snow, C. C. (1978). Organizational strategy, structure and process. New York: McGraw Hill.

Miller, D. and Friesen, P. H. (1982). Innovation in conservative and entrepreneurial firms: two models of strategic momentum. Strategic Management Journal, Vol. 3, No. 1, pp. 1-25.

Mohr, L. B. (1971). Organizational structure and organizational technology. Administrative Science Quarterly, No. 16, pp. 444-459.

O'Connor, N. G. (1995). The influence of organizational culture on the usefulness of budget participation by Singaporean-Chinese managers. Accounting, Organizations and Society, Vol. 20, No. 5, pp. 383-403.

Otley, D. T. (1980). The Contingency Theory of Management Accounting: Achievement and Prognosis. Accounting, Organizations and Society, Vol. 5, No. 4, pp. 413-428.

Patiar, A. and Mia, L. (2008). The interactive effect of market competition and use of MAS information on performance: Evidence from the upscale hotels. Journal of Hospitality and Tourism Research, Vol. 32, No. 2, pp. 209-234. 
Pennings, J. (1975). The relevance of the structural-contingency model for organizational effectiveness. Administrative Science Quarterly, Vol. 30, pp. 393-410.

Perrow, C. (1970). Organizational analysis: a sociological view. California: Wadsworth Publishing Company.

Porter, M. E. (1980). Competitive Strategy. New York: The Free Press.

Saudagaran, S. M. and Diga, J. G. (1999). Evaluation of the contingency based approach in comparative international accounting: A case for alternative research paradigms. Journal of Accounting Literature, Vol. 18, pp. 57-95.

Schoonhoven, C. B. (1981). Problems with contingency theory: testing assumptions hidden within the language of contingency "theory". Administrative Science Quarterly, Vol. 26, No. 3, pp. 349-377.

Selto, F. H., Renner, C. J. and Young, S. M. (1995). Assessing the organizational fit of a just-in-time manufacturing system: testing selection, interaction and systems models of contingency theory. Accounting, Organizations and Society, Vol. 20, No. 7/8, pp. 665-684.

Simons, R. (1987). Accounting control systems and business strategy: an empirical analysis. Accounting, Organizations and Society, Vol. 12, No. 4, pp. 357-374.

Sousa, R. and Voss, C. A. (2008). Contingency research in operations management practices. Journal of Operations Management, Vol. 26, pp. 697-713.

Swamidass, P. M. and Newell, W. T. (1987). Manufacturing strategy, environmental uncertainty and performance: a path analytic model. Management Science, Vol. 33, No. 4, pp. 509-524.

Thompson, J. D. (1967). Organizations in action. New York: McGraw Hill.

Tiessen, P. and Waterhouse, J. H. (1983). Towards a descriptive theory of management accounting. Accounting, Organizations and Society, Vol. 8, No. 213, pp. 251-267.

Tsui, J. S. L. (2001). The impact of culture on the relationship between budgetary participation, management accounting systems, and managerial performance: An analysis of Chinese and Western managers. The International Journal of Accounting, Vol. 36, pp. 125 - 146.

Waterhouse, J. H. and Tiessen, P. (1978). A contingency framework for management accounting systems research. Accounting, Organizations and Society, Vol. 3, No. 1, pp. 65-76.

Woodward, J. (1965). Industrial organization: theory and practice. Oxford University Press. 